\title{
Implicações éticas da construção do conhecimento: desafios para a prática da docência e da investigação científica ${ }^{11}$
}

\begin{abstract}
Antonio Joaquim Severino ${ }^{12}$
Resumo: A vida universitária, sob todos os seus aspectos, representa um espaço/tempo fundamentalmente compromissado com a construção e sistematização do conhecimento bem como com o compartilhamento de seus resultados com a sociedade. Daí serem as mediações constitutivas de seu exercício a pesquisa, o ensino e a extensão. Em todas essas tarefas, está em pauta a relação das atividades acadêmicas com a vida social, o que gera exigências para seu desenvolvimento não só epistêmicas, mas também éticas e políticas. Assim sendo, a finalidade deste ensaio é explicitar que estas exigências se implicam mutuamente. Busca então apresentar e debater os desafios postos pelo relativismo ético, decorrente do exacerbado pragmatismo vigente no atual cenário acadêmico, discutindo, particularmente, a questão da exigência da ética na formação e na prática pedagógica dos educadores, de modo especial na esfera da docência e da pesquisa, no contexto universitário. Aborda, em decorrência, o lugar da normatividade legal na interface com a legitimidade ética bem como a relação das determinações heteronômicas, vinculadas à lógica pragmática hegemônica na vida social contemporânea, com a sensibilidade moral que se impõe aos cientistas e ao professores.
\end{abstract}

Abstract: University life, in all its aspects, represents a space / time fundamentally committed to the construction and systematization of knowledge as well as the sharing of its results with society. Hence, the constitutive mediations of its exercise are research, teaching and extension. In all these tasks, the relation between academic activities and social life is on the agenda, which generates not only epistemic but also ethical and political demands for its development. Therefore, the purpose of this essay is to make explicit that these demands imply each other. It seeks, therefore, to present and debate the challenges posed by ethical relativism, arising from the exacerbated pragmatism in the current academic scene, discussing, in particular, the question of the ethics requirement in the formation and pedagogical practice of educators, especially in the sphere of teaching and research, in the university context. It addresses, therefore, the place of legal normativity in the interface with the ethical legitimacy as well as the relation of the heteronomic determinations, linked to the hegemonic pragmatic logic in contemporary social life, with the moral sensitivity that is imposed on scientists and tea

Submetido em: junho de 2017. Aprovado em: novembro de 2017.

\section{Introdução}

Em que pese a existência de múltiplos problemas postos pelo desenvolvimento tecnológico gerado pela ciência, não há como negar a grande contribuição que ela deu

\footnotetext{
${ }^{11}$ Artigo resultante de trabalho apresentado no XVII encontro do NESEF. Curitiba, UFPR, 22 e 23 de junho de 2017.

12 Professor Doutor em Filosofia. Feusp (Emérito). Uninove -Docente da Pós-Graduação e Orientador de Grupo de Pesquisa.E mail: ajsev@uol.com.br
} 
para agregação de qualidade à vida humana. Graças a ela e a esse desdobramento em tecnologia, os homens puderam encontrar meios para melhor conduzir sua existência histórica, viabilizando a disponibilidade e acessibilidade a todos recursos materiais e simbólicos de que precisam para dar mais qualidade a sua vida. Como não reconhecer isso com a potencialização da produção de alimentos, da descoberta de doenças e de medicamentos, do aprimoramento das condições de habitação, locomoção, transportes, da viabilização da produção e da fruição dos bens culturais. Portanto, o papel da ciência é indiscutível para a construção da civilização, para a superação das determinações que condicionavam e aprisionavam o homem em sua relação com a natureza física préhumana. O conhecimento em geral e o conhecimento científico em particular representaram conquistas altamente significativas no desenvolvimento da espécie, uma conquista valiosíssima.

Mas não há como não reconhecer também que o feitiço está virando contra o feiticeiro, as virtudes da postura científica passam a ameaçar essa qualidade... Com efeito, essa poderosa ferramenta que trouxe ao homem recursos para sua emancipação, dando maior sustentação para sua autonomia como sujeito, está atravessando um momento histórico difícil, que gera séria ameaça para que continue sustentando o processo autonomizador, como que se estivéssemos perdendo o controle dele, como se o desenvolvimento científico estivesse assumindo rumos desnorteados e desnorteantes. É como se as boas características qualitativas do conhecimento científico se voltassem contra si mesmas...

Desenha-se então um cenário que tende a dar sustentação permanente a essa ameaça. Estamos atravessando um momento marcado por fortes características que expressam uma tendência da vida social como um todo. Assim, convivemos envoltos numa malha de posturas intimamente ligadas ao desempenho científico e tecnológico, tais como:

Um pragmatismo utilitarista: os conhecimentos são atrelados a suas finalidades práticas e às funcionalidades que propiciam. São descartados ou desqualificados os conhecimentos que não tenham uma utilidade prática. Situações e conhecimentos que não tenham uma utilidade prática tendem a ser marginalizados e considerados inúteis.

Um tecnicismo epistêmico: como a técnica é que expressa melhor essa capacitação funcional, a própria ciência torna-se uma modalidade priorizada de conhecimento e passa a ser desenvolvida de modo igualmente técnico.

A construção de conhecimentos pela mediação da ciência é atropelada pois toda 
sua avaliação se dá pelo volume de sua produção. Daí o produtivismo científico. Exacerba-se a demanda por resultados rápidos e eficazes, fazendo com que a prática científica seja comandada pelo quantitativo em detrimento do qualitativo.

Um relativismo ético generalizado: não há referências éticas que restringissem a absoluta liberdade na produção científica, supostamente em nome da liberdade individual de autonomia e de criação. Isso se dá no contexto da afirmação de um individualismo radical que contamina todo o ambiente cultural e toda a esfera do agir humano.

Tal situação gera obviamente um conflito pois, em que pese toda essa situação histórica bem concreta, a problemática ética continua impregnando capilarmente nossa existência cotidiana com a mesma intensidade que a problemática epistêmica, eis que todas as expressões concretas de nosso existir estão sempre inelutavelmente envolvidas com uma significação conceitual e com uma apreciação valorativa. Não há como escapar. Tal situação é marca constitutiva da condição humana. Em tudo que fazemos, está sempre envolvido algum saber bem como alguma valoração. Isso decorre fundamentalmente da condição de entes dotados de uma dimensão de radical subjetividade, que nos coloca frente aos objetos de nossa experiência. Do ato mais simples ao mais complexo, um equacionamento subjetivo simultaneamente conceitual e valorativo perpassa sua realização concreta.

Não pode então ser diferente quando está em pauta a atividade científica, em todos os seus aspectos, modalidades e momentos. Daí a pertinência, a relevância e a necessidade para os Programas de Pós-Graduação, dada sua condição específica de lugares de produção científica, de abrir espaços para esta discussão.

Mas, cabe indagar: o que funda essa sensibilidade ética? Ela nasce da posição da presença do outro de mim, da força da alteridade. Pois é essa presença que gera a demanda de seu reconhecimento como tal, impondo-me o levar em conta a dignidade de que o mesmo é portador. Não posso, ou melhor, não devo desrespeitar o outro em sua dignidade.

Mas quem são os outros? O outro não é uma entidade abstrata e ideal; ao contrário, é fortemente concretizado e está presente sempre ao meu alcance, se espraiando em círculos concêntricos que me rodeiam, indo desde uma relação de contato físico próximo até uma esfera mais ampla de contato difuso, mais invisível.

Assim, meus primeiros outros são constituídos pelos meus familiares, grupo agregador pelos laços genéticos; depois meus parceiros compostos pelos vários grupos 
de interação; no âmbito do trabalho, do estudo, de recreação, círculos de convivência entre pessoas, identificadas individualmente com nomes próprios. Depois temos os grupos sociais mais amplos com cujos integrantes nossa relação não é direta: a população de meu bairro, de minha cidade, de meu estado, de meu país. É o que se designa como a nossa sociedade. Já é um grupo anônimo mas em relação ao qual eu tenho compromisso.

E, numa esfera mais ampla ainda, há toda a espécie humana, a humanidade como um todo. Para com ela eu também estou vinculado por uma solidariedade de destino. Enquanto um único ser humano estiver sofrendo, passando fome, escravizado, sob situações de opressão e exclusão, eu também não sou totalmente livre e autônomo, não estou plenamente humanizado.

\section{O alcance ético na esfera do proceder científico.}

Essa sensibilidade à problemática ética se expressa em todos os espaços em que a vida acadêmica e científica se desenrola. Não se dá apenas na dimensão filosófica, sob inquietações solitárias de estudiosos isolados. Ganha ressonância nos mais variados lugares culturais e institucionais, produzindo repercussões e induzindo medidas que causam impacto na vida cotidiana das comunidades, pois o que está em jogo afeta todas as pessoas, sem exceção. Invade até as esferas do senso comum.

Vejamos alguns exemplos dessas repercussões... Em nosso contexto, elenco algumas situações bem representativas. É o caso de iniciativa do CNPq que, ao longo de 2011, reagindo às frequentes ocorrências de fraude em publicações científicas, envolvendo inclusive pesquisadores apoiados por ele, e preocupado com a necessidade de boas condutas nas pesquisas científicas e tecnológicas, instituiu uma Comissão Especial formada por cientistas brasileiros de grande experiência e liderança, com a missão de propor recomendações e diretrizes sobre o tema da ética e integridade na prática científica, seja na sua realização, seja na sua divulgação. A Comissão apresentou seu relatório final fazendo recomendações ao $\mathrm{CNPq}$, propondo ações preventivas e educativas e ações de desestímulo a más condutas e até mesmo medidas punitivas. Propôs também que o órgão criasse uma Comissão Permanente de Integridade Científica para acompanhar e cuidar da prática científica no país.

Já em 2010, o Conselho Federal da OAB aprovou uma recomendação formal a todas as Instituições de Ensino Superior do país, propondo medidas concretas e eficazes visando coibir o plágio nas atividades acadêmicas. O que preocupava a OAB era a 
proliferação de trabalhos acadêmicos feitos mediante a apropriação de produções alheias, sem a atribuição dos créditos devidos, caracterizando-se graves delitos. Tais ocorrências tornaram-se facilmente operacionalizáveis graças aos recursos da Internet e da informática. De acordo com a justificativa apresentada pelo relatório da OAB, "a desonestidade moral e intelectual disseminou-se de tal forma que alguns alunos traduzem monografias inteiras de outros idiomas por ferramentas eletrônicas e intitulam-se autores dos trabalhos. Alguns estudantes chegam ao absurdo de comprar monografias de terceiros para colocar seu nome na autoria" (2010, p. 2. Destaque no original).

Esta proposição foi assumida pela CAPES que a repassou a todos os Programas de Pós-Graduação do pais, endossando-a integralmente e reforçando "a necessidade de combate ao plágio onde quer que este se manifeste" (2011, p. 2)

Essas iniciativas surgiram da crescente ocorrência de práticas no âmbito acadêmico e científico que têm conturbado e ameaçado o ambiente de produção do conhecimento, tais como fabricação e invenção de dados, falsificação de resultados, plágios e autoplágios. Embora os processos denunciados sejam mais de natureza epistêmica, comprometendo a validade dos conhecimentos produzidos, a situação tem repercussão no plano ético, na medida em que traduz um relaxamento no compromisso do pesquisador com a fidedignidade de suas ações propriamente científicas.

A necessidade de se tomar medidas normativas e punitivas com relação a essas práticas consideradas como más condutas reflete um clima de insegurança com relação à postura dos pesquisadores e traz à baila o debate sobre os diversos aspectos que envolvem a dimensão ética na investigação científica.

Começo lembrando que o questionamento ético relacionado ao comportamento humano se coloca em três esferas bem abrangentes, ou seja, as manifestações concernentes à perspectiva ética bem como os esforços para objetivá-las em normas positivas podem ser vistas desses três ângulos. Obviamente que embora parecendo recortes distintos, são complementares e interligados entre si.

De um primeiro ponto de vista, podemos considerá-la em sua interface com o macrossocial, quando estão em pauta iniciativas que envolvem sociedades e estados. Nesse caso, estamos diante de tomadas de decisão e de práticas bem abrangentes, atingindo toda a humanidade. Como exemplos, podemos tomar, além das guerras, situações como aquelas decorrentes do desenvolvimento e de aplicação de tecnologias que trazem ou podem trazer ameaças e danos para as sociedades humanas: os casos da 
utilização da energia nuclear, das armas químicas e biológicas, as pesquisas genéticas, as pesquisas ambientais. De forma que não predar ou poluir o ambiente natural, não maltratar os seres vivos tornam-se imperativos de valor ético, gerando cobrança por políticas públicas e de normas que coíbam tais ações e punam os infratores. Peter Singer elenca o cuidado com o ambiente e o tratamento atroz que é dado aos animais como dois graves desafios éticos da humanidade nos dias atuais. Esta é uma perspectiva em que a ética assume uma conotação eminentemente política. (SINGER, 2013, p. 12-13). O compromisso cobrado do indivíduo decorre do compromisso mais amplo que ele tem com a sociedade em seu conjunto, com a polis.

De um segundo ângulo, podemos considerar aquelas situações internas a grupos mais restritos, quando comportamentos de pessoas, isolada ou coletivamente, ferem direitos e dignidade de outras pessoas ou grupos. Por exemplo, na manipulação desonesta de recursos comuns, na exploração dos mais fragilizados, na apropriação indébita de resultados e de esforços de outros. Estamos aqui diante de situações mais objetivadas para a prevenção das quais se criaram os códigos de ética, que se empenham em descrever e traduzir, mediante normas de direito positivo, os procedimentos considerados inadequados, eticamente condenáveis e juridicamente penalizáveis. Embora mais localizadas em espaços menores, estas situações também envolvem o ético com o político, num círculo menos abrangente.

Mas o pesquisador se envolve ainda numa situação mais subjetivada, que depende mais intensamente de sua opção pessoal. É quando, com suas decisões e ações pessoais, possa estar ferindo direitos de terceiros, quando atinge outras pessoas individuais, fraudando, no microcosmo de sua prática, determinados princípios éticos. Aqui está em questão o agir pessoal de cada um, visto no seu impacto sobre as outras pessoas com as quais se relaciona.

\section{As injunções éticas decorrem da presença interpelante da alteridade....}

$\mathrm{Na}$ complexidade das situações reais, muitas vezes, todas estas situações se sobrepõem, de tal modo que os sujeitos as vivenciam simultaneamente, gerando implicações para suas opções. Mas, isoladas ou interligadas, em todas essas situações, está suposta uma esfera comum de significação do ético. É esse núcleo comum que define a eticidade das ações humanas. E para que se possa falar de uma referência ética, duas condições são postas como que a priori: a primeira, a presença da alteridade, a presença do outro; a segunda, o reconhecimento da dignidade da pessoa humana. Assim 
a ética envolve, de forma dialética, a presença de um eu frente a um outro. Ao mesmo tempo que ela supõe um exercício radical da subjetividade mais íntima do próprio eu, ela supõe, com igual necessidade, a objetividade do outro que coloca em frente do eu a sua alteridade.

Aqui cabe fazer, de forma bem incisiva, um destaque muito especial sobre a ética na docência, pois na maioria de nossos casos, é neste âmbito que temos de desenvolver com mais tempo e intensidade, as nossas atividades acadêmicas, portanto, é o lugar de maior incidência de nosso encontro com o outro, é onde e quando o outro nos interpela diretamente. Estou me referindo às relações entre professores e alunos, às relações dos professores entre si, dos alunos entre si, de alunos, professores, funcionários e gestores, entre todos, ou seja, na comunidade escolar, em geral, e na comunidade acadêmica, universitária, em particular. Este é o espaço mais concreto e onde somos mais interpelados pelas demandas éticas, pois é aí que ocorre o cotidiano de nossa atividade profissional. Evidentemente, todas as categorias profissionais que lidam com público encontram-se em idêntica situação e a grande maioria delas já criou seu código de ética. Este é uma tentativa de estabelecer um padrão de conduta que elenca os limites objetivos dos modos de se proceder no seu campo de atividade, procurando impedir que determinadas posturas, atitudes e falas que potencialmente podem agredir a dignidade de um outro sejam postas. Curiosamente, a categoria dos professores não fez o seu código de ética. Talvez isso se deva à própria dificuldade de se formar uma associação efetivamente representativa dessa categoria. Mas a ausência de um código de ética, formal e oficializado, não deveria ser uma desculpa para um comportamento antiético por parte dos profissionais da educação. Isso porque na prática educativa, a ética já é um elemento intrínseco da própria atividade, ela integra o processo formativo. E esse processo formativo, do qual a docência é mediação fundamental, inclui como elemento necessário a própria postura pessoal do professor, sua atitude tem papel substantivo de exemplaridade. Daí a procedência do questionamento do descaso na condução responsável das tarefas didáticas, na preparação das aulas, na avaliação etc, do bullying docente, das formas de agressão física ou verbal, dos gestos que humilham o aluno, enfim de todas as formas sutis de violência simbólica, que encarnem desrespeito à dignidade dos alunos.

Obviamente, assim como o aluno é um outro para o professor, merecendo reconhecimento e respeito, o professor é igualmente um outro para o aluno e, do ponto de vista ético, tudo que é dito quanto à postura do professor se aplica também ao aluno. 
Igualmente, também não é aceitável o bullying dos alunos para com seus professores bem como qualquer outra forma de violência física ou simbólica.

Exigências análogas devem ser consideradas em relação às atividades de extensão nas quais, o mais das vezes, o público alvo é constituído de outros ainda mais vulneráveis.

Assim, na prática convivial dos docentes e demais sujeitos envolvidos na educação, como parceiros de jornada em torno de um projeto comum, a demanda ética não deveria vir do acatamento de normas regimentais positivadas, mas da sensibilidade à dignidade do outro como pessoa humana. Essa condição de dignidade pessoal gera, para todos os sujeitos em relação entre si, múltiplos direitos: a começar pelo direito a ter uma identidade diferente, a ter características próprias que geram uma condição existencial de diferença, mas nunca deve geram uma condição de desigualdade. Para se respeitar a pessoa do outro, é preciso reconhecer e respeitar os seus direitos, que não podem ser sonegados, deturpados ou desqualificados.

Outro direito é o da autonomia de sua consciência. Este é um direito crucial no caso da relação docente, pois o aluno encontra-se, frente ao professor, numa posição de fragilidade estrutural e funcional na disponibilização dos espaços e no manejo dos conceitos e valores que são ferramentas da educação. Daí o risco de posturas de autoritarismo e de doutrinação. Este é mesmo um âmbito delicado pois, na relação docente, é preciso haver autoridade, mas sem cair no autoritarismo. É preciso compartilhar ideias plurais, mas sem ideologizar, sem doutrinar, atitudes que suscitam reações anômalas como a proposta de uma escola sem partido, que, por sua vez, acaba por desrespeitar a autonomia e a dignidade do professor.

\section{O que está em pauta é uma exigência ético-política...}

Mas, voltando ao que disse de início, com a defesa da autonomia e da diferença de cada um, não se trata de endossar o individualismo exacerbado que tende a predominar no cenário atual, dominado por um relativismo ético radicalizado. É por isso mesmo que a necessária consideração da presença do outro, como condição de qualquer eticidade, faz com que os sentidos de ética e de política se entrelacem intimamente. Trata-se de uma vinculação intrínseca e íntima. Não há como distinguir a qualidade ética de uma ação de sua qualidade política. A presença do outro em toda e qualquer circunstância da ação moral faz com que toda ação envolva necessariamente as 
duas dimensões ao mesmo tempo, a ética e a política. Embora no discurso corrente, é comum usar separadamente os conceitos, toda ação humana, sob a perspectiva moral, é ético-política. O uso separado dos conceitos e dos termos visa apenas enfatizar o aspecto mais pessoal, quando se usa o termo ético, e o aspecto mais social, quando se usa o termo político.

Para clarear um pouco mais nossa questão, recorro às contribuições de Paul Ricoeur a respeito da ética, posições que considero fecundas para nos guiar nessa empreitada. De acordo com esse filósofo, a vivência ética recobre todo o espaço da existência histórica do homem, podendo ser expressa sob a seguinte formulação: "viver bem com e para os outros em instituições justas". São assim três momentos: o viver bem (o si mesmo), com e para os outros (dada a presença do outro), e em instituições justas (dada a necessidade de mediações objetivas para que o convívio entre as pessoas não seja sufocado pela violência).

Temos assim um primeiro momento em que prevalece a sensibilidade ética pessoal; um segundo momento em que prevalece a moralidade e um terceiro momento em que atua o julgamento, momento que Ricoeur designa como o momento da sabedoria prática. $\mathrm{Na}$ concepção de Ricoeur, estão presentes todos os elementos fundamentais da vivência ética ou da eticidade da existência humana: a sensibilidade do sujeito pessoal aos valores fundados na dignidade da condição de pessoa autônoma; a presença e a interação com o outro, o dado da alteridade, em que o outro se coloca como igualmente sujeito pessoal dotado de igual dignidade; a objetividade das circunstâncias da vida e a necessidade das instâncias institucionais como região e garantia das normas da convivência com outros, numa relação de justiça, e, finalmente, a necessidade e a capacidade de todos de formularem um juízo moral situado.

Mas há que acrescentar aí uma quarta exigência. É preciso ainda que possamos viver num ambiente natural saudável, resultante da preservação do planeta Singer (2014). É como se houvesse ainda a necessidade de um termo de convivência dos homens, não só com seus semelhantes, sob a égide de um contrato social (Rousseau) mas também com a natureza física, sob a égide de um contrato natural (1997), Serres (1994 ) e Morin (1991, 1996). Como sintetiza bem Gadotti (2000, 2003) em seus escritos sobre a Pedagogia da Terra e sobre a educação com sustentabilidade:

"Não entendemos o universo como partes ou entidades separadas, mas como um todo sagrado, misterioso, que nos desafia a cada momento de nossas vidas, em evolução, em expansão, em interação. (...) O Paradigma-Terra é um paradigma 
civilizatório. E como a cultura da sustentabilidade oferece uma nova percepção da Terra, considerando-a como uma única comunidade de humanos, ela se torna básica para uma cultura de paz." (2003, p. 52)

\section{Conclusão}

Para concluir, cabe refletir sobre qual o fundamento, o que legitima a sensibilidade ética... De onde vem o valor dos valores? Onde se funda a consciência moral? Se o homem é um ser histórico em construção, em devir, sem vinculação determinante à essência metafísica e à natureza física, naquilo que lhe é específico, onde ancorar a referência valorativa de sua consciência moral? O valor fundante dos valores que fundam a moralidade é aquele representado pela própria dignidade da pessoa humana, ou seja, os valores éticos fundam-se no valor da existência humana. É em função da qualidade desse existir, delineado pelas características que lhe são próprias, que se pode traçar o quadro da referência valorativa, para se definir o sentido do agir humano, individual ou coletivo. Ou seja, o próprio homem já é um valor em si, nas suas condições de existência, na sua radical historicidade, facticidade, corporeidade, incompletude e finitude, enfim, na sua contingência. Não porque buscar outro fundamento fora dele mesmo.

Note-se que à luz do entendimento filosófico, a dignidade humana é um valor e não uma essência descritiva de sua realidade concreta, em decorrência da qual o homem é um ser natural como todos os demais seres do planeta. Sua diferenciação vem da capacidade de se configurar como portador de uma qualificação valorativa e não meramente conceitual. Os homens se atribuem então um índice qualitativo de valoração que os torna merecedores de respeito, todos os indivíduos da espécie tornando-se sujeitos de dignidade, a qual não pode ser agredida e violentada. As exigências éticas decorrem, em última análise, do necessário respeito a essa dignidade.

É sob essa significação que deve ser entendida e praticada toda mediação de nossa existência histórica, como o é o caso exemplar da educação bem como de todas as demais práticas humanas a ela relacionadas como a ciência e a pesquisa.

Nunca é demais repetir que a finalidade da educação é a humanização, a formação das pessoas humanas, e mais do que qualquer outra prática social, cabe a ela, nessa condição, investir na construção da autonomia das pessoas, respeitando e consolidando sua dignidade. Trata-se da própria construção do ser humano que não é 
dado como pronto e acabado, mas como um ser a ser construído, num processo permanente de um vir-a-ser, de um tornar-se humano. Pois ao emergir na superfície da biosfera, o homem é um ser totalmente imanente numa infra-estrutura existencial que o prende por fortes amarrios a uma série de a prioris existenciais, intrínsecos às pulsões da vida. Mas o processo de construção do humano, a humanização, não é um processo linear e harmonioso. Ele é conflituoso em decorrência da caminhada que tem de ser conjunta com o outro, que pode tornar-se uma ameaça para a própria identidade do eu em construção. É o conflito e o confronto das diferenças, ameaça contínua a toda identidade. A educação se situa no emaranhado seio desse conflito permanente....

O cuidado ético não é uma exigência apenas das intervenções do ensino e da extensão, mas igualmente da pesquisa, porque a ciência não é mesmo decorrente apenas de uma prática puramente técnica e inocente (FORPRED, 2013, p. 4)

\section{REFERÊNCIAS}

ARROYO, Miguel A. Conhecimento, ética, educação e pesquisa. E.Curriculum, São Paulo, v. 2, n. 2, jun 2007, p. 1-8.

BIANCHETTI, Lucídio \& MACHADO, Ana M. N. Reféns da produtividade: sobre produção do conhecimento, saúde dos pesquisadores e intensificação do trabalho na pós-graduação. Caxambu: Anped, 2006. Trabalho apresentado no GT. Educação e Trabalho.

CAPES. Orientações Capes: combate ao plágio. Brasilia: Capes, 2011.

CONEP. Carta ao GT da Resolução sobre Ética em Pesquisa nas Ciências Humanas e Sociais. Brasilia. 03 de julho de 2014. Disponvível em http://conselho. saude.gov.br/web_comissoes/conep/aquivos/CartaCircular100-2014.pdf

CONSELHO FEDERAL DA OAB. Comissão Nacional de Relações Institucionais. Proposição 2010.19.07379-01. Brasília: Ỏ, OA, 2010; [www.oab.org.br/combateplagio/CombatePlagio.pdf].

DELLA ROSE, Valter A. Formação de professores do PARFOR: breves comentários sobre a ética na saúde e na ciência. In: PAINI, Leonor D.; COSTA, Cecília M. da;

VICENTINI, Max R. (Orgs.) Parfor: integração entre Universidade e Ensino Básico diante dos desafios na formação de professores do Paraná. Maringá: EDUEM, 2014. p. 185-194.

DINIZ, D. Ética na pesquisa em ciências humanas: novos desafios. Revista Ciência e Saúde Coletiva. Rio de Janeiro, v. 13, nl 2 mar./abr. 2008, p. 417-426. 
FARE, Monica de la; MACHADO, Frederico V.; CARVALHO, Isabel C. de M. Breve revisão sobre regulação da ética em pesquisa: subsídios para pensar a pesquisa em educação no Brasil. Práxis Educativa. Ponta Grossa, v. 9, n. 1,. Jan./jun. 2014. p. 247283

FORPRED. Breve síntese do Seminário sobre Etica na Pesquisa em Educação promovido pelo Forpred Sudeste e PPG Educação/Unicamp. Campinas: Unicamp, 2013.

GADOTTI, Moacir. Pedagogia da terra e cultura da sustentabilidade. In: ROMÃO, José E.; OLIVEIRA, José E. (Coords.) Questões do século XXI. São Paulo: Cortez, 2003. p. 48-57.(Col. Questões de Nossa Época.Vol.100,Tomo I).

GADOTTI, Moacir. Pedagogia da terra. São Paulo: Peirópolis, 2000.

HOSSNE, William S. e VIEIRA, Sonia. Fraude em ciência: onde estamos. Revista Bioética, vol. 15, no. 1, 2007. p. 39-47.

KUNG, Hans. Uma ética global para a política e a economia mundiais. Petrópolis: Vozes, 1999.

MORIN, Edgar; KERN, Anne Brigitte, Terra Pátria. Porto Alegre: Sulina, 1996.

MORIN, Edgar. O método, vol.1. A natureza da natureza. Publicações Europa-América, 1991.

NOVOA, António. Em busca da liberdade nas universidades: para que serve a investigação em educação? Revista Lusófona de Educação. Lisboa, no. 28, p. 11-21.

RICOEUR, Paul. Da metafísica à moral. Lisboa: Instituto Piaget, 1995.

ROUSSEAU, Jean-Jacques. Do contrato social. Ensaio sobre a origem das línguas. São Paulo: Nova Cultural, 1997.(Coleção Os Pensadores).

SERRES, Michel. O contrato natural. Lisboa: Instituto Piaget, 1994.

SEVERINO, Antonio J. Dimensão ética da investigação científica. Revista Práxis Educativa, UEPG, Ponta Grossa. Vol. 9, N 1, 2014. p. 199-208.

SINGER, Peter, O dever de evitar o mal. Jornal da USP. Ano 29, no. 1011. 9-15 setembro de 2013, p.12-1)

VON ZUBEN, Newton A. Bioética e tecnociências: A saga de Prometeu e a esperança paradoxal. Bauru: EDUSC, 2000. 